\title{
Study of an Extraction Process as the Pretreatment Step for Sugar Production from Acid Hydrolysis
}

\author{
Sylvia C. Alcázar-Alay, Fiorella P. Cardenas-Toro, Diego T. Santos, M. Angela A. Meireles* \\ LASEFI/DEA/FEA (School of Food Engineering), UNICAMP (University of Campinas), Rua Monteiro Lobato, Brazil
}

\begin{abstract}
This work involves the residues of three plant species used in industry: Brazilian ginseng (Pfaffia glomerata), palm (Elaeis guineensis) and annatto (Bixa orellana L.). The studied plant residues come from oil and biocompounds extraction: Soxhlet extraction (SE), Pressurized liquid extraction (PLE) and Supercritical fluid extraction (SFE). The effects of these extraction processes on the structures of plant matrices were observed using scanning electron microscopy (SEM). Plant residues were subjected to acid hydrolysis. The hydrolysis process was conducted using a $0.5 \mathrm{~L}$ reactor at atmospheric pressure and the solvent at boiling temperature. Brazilian ginseng was hydrolyzed in hydrochloric acid solution $(0.5,2.5$ and $5.0 \%, \mathrm{v} / \mathrm{v})$ for $60 \mathrm{~min}$. Palm pressed fiber and annatto were hydrolyzed in sulfuric acid solution $(1.5$ and $3.0 \%, \mathrm{v} / \mathrm{v})$ for $90 \mathrm{~min}$. Sugars produced by the hydrolysis were quantified and interpreted as Reducing sugars (RS) (g glucose/100 g raw material) and Total reducing sugars (TRS) (g sucrose/100 g raw material) by a spectrophotometric method. The results observed by SEM showed that the extraction treatments modified the vegetable matrix with respect to its structure and component ratio. The acid hydrolysis process of each vegetable matrix showed different reaction kinetics. The availability and source of the sugar polymers and the acid concentration were variables that affected the hydrolysis reaction.
\end{abstract}

Keywords Biomass, Hemicellulose, Cellulose, Starch, Acid Hydrolysis, Sugar

\section{Introduction}

Different extraction techniques are important alternatives for the recovery of compounds from plants and other vegetal materials [1]. Most extraction techniques are based on the abilities of solvents and heat to increase the mass transfer and solubility of compounds [2]. The objective of an extraction process in vegetable matrices is to separate the substances of interest from cellular structures by diffusion or breaking the vegetal tissues [3]. Conventional extraction techniques include Soxhlet extraction (SE), maceration, percolation and hydrodistillation [4]. Unconventional extractions include Microwave assisted extraction (MAE), Ultrasound-assisted extraction (UAE), Pulsed-electric field extraction (PEF), Enzyme-assisted extraction (EAE), Supercritical Fluid Extraction (SFE), Pressurized Liquid Extraction (PLE), etc. [2].

The SE process was designed primarily for lipid extraction; and, has found application in the extraction of valuable bioactive compounds from various natural sources [5]. The use of SE remains prevalent in industry despite needing a long process time and large amounts of solvent [4]. During $\mathrm{SE}$, continuous contact between the vegetable matrix and the

* Corresponding author:

maameireles@gmail.com (M. Angela A. Meireles)

Published online at http://journal.sapub.org/fph

Copyright (C) 2015 Scientific \& Academic Publishing. All Rights Reserved solvent is maintained using intermittent reflux. The solvent containing the dissolved material is drawn via a siphon and is discharged into a distillation apparatus, and this process occurs repeatedly until the complete extraction time [6].

A PLE process uses pressure to keep a solvent in the liquid phase above its normal boiling temperature [7]. The solubility of compounds and mass transfer rate increase at high temperature, lowering the viscosity and surface tension of the solvent, which improves the extraction rate [8]. Nonetheless, for some raw materials PLE is not a recommended technique as demonstrated by Rodrigues et al. [9].

Supercritical fluids are used as the extracting solvent in SFE; carbon dioxide is the most commonly used supercritical solvent. This state of matter is achieved when the solvent is subjected to a temperature and pressure above the critical point where there is no distinction between the liquid and gas phases [10]. Some properties of the supercritical fluid are similar to the gas phase, such as diffusion, viscosity and surface tension, whereas the density and solvation power are comparable to the liquid phase [11]. These properties increase the extraction rate and yield [12].

Extraction processes can be considered as pretreatments before further processing of the vegetal biomass [13, 14]. Extractions require preparatory treatments, such as drying and grinding [15]. Together these processes physically modify the vegetable matrix [16].

Several crops generate a large amount of biomass 
(lignocellulosic and starch). However, not all of this biomass is used by industry. An alternative is to use this biomass as a feedstock for the production of oligosaccharides and monosaccharides by hydrolysis due to the large availability and lower cost of vegetal biomass and the need to reduce waste production [17-19]. These sugar oligomers and monomers can be included in industrial processes for food, chemicals and sustainable energy production $[20,21]$.

Acid hydrolysis can be performed using concentrated or dilute acid solutions. Dilute acid solutions are especially useful when lignocellulosic biomass has a significant proportion of hemicellulose because the hemicellulosic fraction is more easily hydrolyzed than cellulose [22]. The hydrolysis process with dilute acid solutions facilitates the neutralization process but has a lower yield of glucose from cellulose [23]. Concentrated acid solutions require lower processing temperatures and pressures, and the hydrolysis reaction occurs at a lower process time [22]. Acid hydrolysis using concentrated acid solutions produces high yield of glucose from cellulose. In lignocellulosic hydrolysis from biomass, sulfuric acid is commonly used, although other mineral acids, such as hydrochloric, nitric and phosphoric acid are also used [24]. The major problems in acid hydrolysis processes are the utilization of corrosive and toxic solvents, the need to neutralize the reaction medium after the hydrolysis process and the subsequent solid waste disposal [25].

Ginseng is a common name used for various plants of the Panax genus, particularly Asian ginseng (Panax ginseng) and American ginseng (Panax quinquefolium), and both species are the most commonly used in the pharmaceutical, cosmetic and food industries. Species of the Pfaffia genus, such as Pfaffia glomerata, belong to the Amaranthaceae family and are Brazilian substitutes for plants of the Panax genus; these species are popularly called Brazilian ginseng [26-29]. Brazilian ginseng roots (BGR) are used in herbal medicine and as a dietary supplement due to anti-inflammatory and analgesic properties [27], as well as cellular stress and immunological effects $[28,30]$.

Palm pressed fiber (PPF) is one of the major agroindustrial residues in Brazil. PPF is derived from palm oil production. Palm oil is an edible vegetable oil derived from the fruits of palm trees, primarily the African palm tree (Elaeis guineensis). This palm is grown in humid tropical climates. Palm oil, also known as dendê oil, has a reddish color because of its high carotenoids content [31]. Carotenoids are substances with potent biological and antioxidant activities and are considered precursors for the synthesis of vitamin A. The residues from palm oil extraction are usually burned as fuel despite containing a significant amount of remaining oil and can be a great source of lignocellulosic material $[19,32]$.

Annatto (Bixa orellana L.) is a shrub native to the tropical regions of South America. Annatto fruits are capsules named Cachopas, and these capsules open and have seeds arranged in series when ripe. On the surface of the seeds is the annatto pigment, ranging in color from orange to red [33]. Annatto has been used in traditional cooking since pre-Columbian times and is also used in cosmetic and pharmaceutical products. The principal pigment in Annatto seeds is apocarotenoid bixin, a derivate from dicarboxylic acid norbixin [34]. Currently, several extraction processes are available in industry to obtain this pigment. Extraction techniques include immersing the seeds in hot vegetal oil, using alkaline solutions and extraction with solvent. After removing coloring substances, the residue fraction represents approximately the entire biomass; however, these annatto seeds are considered waste after pigment extraction [9, 33, 35]. Vegetal residue formed by annatto seeds is extremely rich in starch and lignocellulosic material.

In this study, solid residues of the above-mentioned plant after SE, SFE and PLE processes were subjected to hydrolysis using acid solutions at different concentrations and compared to the original raw material. The aim of this study was to: i) determine whether pretreatment coupled with extraction modified the original lignocellulosic structure and ii) establish an association between pre-treatment and extraction processes that improve the production of oligomers and monomers of sugar by acid hydrolysis.

\section{Material and Methods}

\subsection{Raw Material}

The fresh BGR was obtained from CPQBA (Campinas, Brazil). The raw material was conditioned by washing. Next, the samples were dried with air-forced circulation at $40^{\circ} \mathrm{C}$ for 120 hours until a final moisture content of $8.9 \%$. The washing and drying treatments of BGR enabled a subsequent grinding step using a knife mill (TECNAL, model TE-631, Piracicaba, Brazil). The residual raw material of BGR was obtained after the PLE process using water as the solvent. The conditions of the PLE process were a temperature of $60^{\circ} \mathrm{C}$, pressure of 120 bar and Solvent/Feed ratio (S/F) of 4.5 $(\mathrm{w} / \mathrm{w})$.

A PPF sample was provided by Agropalma Company (Tâilandia, Brazil). Raw material was ground in a knife mill (TECNAL, model TE-631, Piracicaba, Brazil) for a few seconds. The PPF residue was obtained after a 6-hour SE process using petroleum ether as the solvent.

Annatto was obtained from the Instituto Agronômico de Campinas-IAC (Agronomic Institute of Campinas) (Campinas, Brazil). Defatted annatto seeds (DAS) were obtained by two processes: a 6-hour SE process using petroleum ether as the solvent and a SFE process using supercritical $\mathrm{CO}_{2}$ as the solvent and parameters established by Albuquerque and Meireles [35]. Untreated annatto seeds and DAS obtained after fat extractions were ground in a knife mill (TECNAL, model TE-631, Piracicaba, Brazil) for a few seconds.

All the raw materials used in this study were kept under refrigeration $\left(-18^{\circ} \mathrm{C}\right)$ and protected from light until used in 
the acid hydrolysis experiments.

\subsection{Characterization of Raw Materials}

The moisture contents of vegetal raw materials were analyzed before the extraction processes [36]. On a dry basis, the lipid [37], protein [38] and ash contents were determined [39]. The carbohydrate content, including starch and lignocellulosic material, was estimated by taking the difference of the experimentally determined components.

\subsection{Scanning Electron Microscopy (SEM)}

Vegetal structures were imaged before and after undergoing SE, PLE and SFE processes using SEM in the Analytical Laboratory of Resources and Calibration (LRAC) at the School of Chemical Engineering (FEQ/UNICAMP, Campinas, Brazil). A metallic sputter coating was made (Sputter Coater POLARON SC7620, VG Microtech, Uckfield, England) with a thickness of $92 \AA$ using gold as the metal and argon as the inert gas. To obtain the micrographs, a scanning electron microscope was coupled with an energy dispersive detector X-ray (Leo 440i, 6070, LEO Electron Microscopy/Oxford, Cambridge, England); an acceleration voltage equal to $15 \mathrm{kV}$ and a beam current equivalent to 150 pA was used.

\subsection{Acid Hydrolysis}

Vegetal material (before and after extraction processes) was hydrolyzed at atmospheric pressure with the selected acid solution in a device designed with a glass flask $(0.5 \mathrm{~L})$ connected to a refrigeration column. For all the experiments, the raw material/acid solution ratio was $5 / 100(\mathrm{w} / \mathrm{w})$. The operating temperature was the boiling solution temperature at atmospheric pressure. The flask containing the acid solution was heated until boiling; the starting process time was taken immediately after adding the raw material.

\subsubsection{Acid Hydrolysis Using Hydrochloric Acid Solution - BGR}

The operating conditions were as follows: hydrochloric acid solution using three concentrations $(0.5,2.5$ and $5.0 \%$ $(\mathrm{w} / \mathrm{w}))$, processing time from zero to $60 \mathrm{~min}$. At each set time $(10,20,30,45$ and $60 \mathrm{~min})$, aliquots were removed in sufficient quantity for analysis.

\subsubsection{Acid HYDROLYSIS ACID USING SULFURIC ACID SOLUTIon - PPF and DAS}

The operating conditions were as follows: sulfuric acid solution using two concentrations $(1.5$ and $3.0 \%(\mathrm{w} / \mathrm{w}))$, processing time from zero to $90 \mathrm{~min}$. At each set time $(10,20$, $30,45,60$ and $90 \mathrm{~min}$ ), aliquots were removed in sufficient quantity for analysis.

\subsection{Reducing Sugars (RS) and Total Reducing Sugars (TRS)}

During the hydrolysis processes, $1 \mathrm{~mL}$ aliquots were removed at each set of analysis time. These aliquots were analyzed for their concentrations of RS and TRS using the colorimetric method of Somogyi-Nelson [40] by spectrophotometry (Femto, model 800 XI, São Paulo, Brazil). For TRS quantification, the test samples were hydrolyzed with a hydrochloric acid solution $(2 \mathrm{~N})$ for $6 \mathrm{~min}$ at the boiling temperature, and then cooled and neutralized with a sodium hydroxide solution $(2 \mathrm{~N})$ to ensure that all the oligosaccharides were hydrolyzed into monosaccharides and would be detectable using the same colorimetric technique. RS and TRS concentrations were calculated using an external calibration curve; the RS and TRS concentrations were interpreted as glucose equivalent and sucrose equivalent, respectively. All the reagents used were of analytical grade.

\section{Results and Discussion}

\subsection{Raw Materials Characterization}

The centesimal composition of plant material before the extraction treatment, on a wet basis, is shown in Table 1. For all materials studied, the presence of carbohydrates was significantly high.

Table 1. Centesimal composition (wet basis, \%)

\begin{tabular}{cccc}
\hline & $\begin{array}{c}\text { Brazilian ginseng } \\
\text { roots (Pfaffia } \\
\text { Glomerata) }\end{array}$ & $\begin{array}{c}\text { Pressed palm } \\
\text { fiber (Elaeis } \\
\text { guineensis) }\end{array}$ & $\begin{array}{c}\text { Annatto } \\
\text { seeds (Bixa } \\
\text { orellana } \text { L.) }\end{array}$ \\
\hline Moisture & $9.87 \pm 0.02$ & $3.8 \pm 0.1$ & $13.5 \pm 0.2$ \\
Lipids & $0.56 \pm 0.02$ & $6.7 \pm 0.9$ & $2.0 \pm 0.2$ \\
Protein & $2.7 \pm 0.3$ & $6.5 \pm 0.2$ & $13.0 \pm 0.2$ \\
Ash & $3.1 \pm 0.2$ & $3.2 \pm 0.2$ & $3.9 \pm 0.7$ \\
Carbohydrates & 84 & 80 & 68 \\
\hline
\end{tabular}

The materials studied are potential substrates for the hydrolysis reaction before and after the extraction pretreatments. Important bioactive components must be extracted first due to the use of these compounds in the food, chemical and pharmaceutical industries.

\subsection{Pretreatments Effects}

The BGR was subjected to an extraction process using pressurized water. As shown in Figure 1, and comparing the plant material structures, the vegetal structure is visibly changed due to the PLE process. Some cellular components of BGR have been removed with the solvent during the extraction. Sample of BGR has a porous appearance and an expanded cellular structure, possibly due to the path in which the solvent diffuses into the vegetal matrix.

The cellular wall in Figure 1 (A) resembles the structure of cellulose and hemicellulose [14]. Considering the extraction temperature and pressure used during the PLE process, possibly, water has participated as a hydrolysis medium for hemicellulosic materials [41]. This result could be explained by Figure 1 (B), where the BGR sample cell wall had cellulosic order and spaces that were not visible by SEM 
before the PLE process.

In Figure 2, the PPF raw material can be observed. A cell wall composed of cellulose fibers arranged in a certain order and presumably connected by lignin is shown $[19 ; 20]$. After the expelling (pressing) process, as shown in Figure 2 (A), PPF still has a significant amount of lipids. During the SE treatment, lipids remain going through these fibers and forming small pores in the lignocellulosic structure as shown in Figure 2(B). Lipid molecules are soluble in the extracting solvent and form a path through the lignocellulosic biomass. Apparently, the lignocellulosic material is not soluble in the solvent used for this extraction and did not react with this solvent.
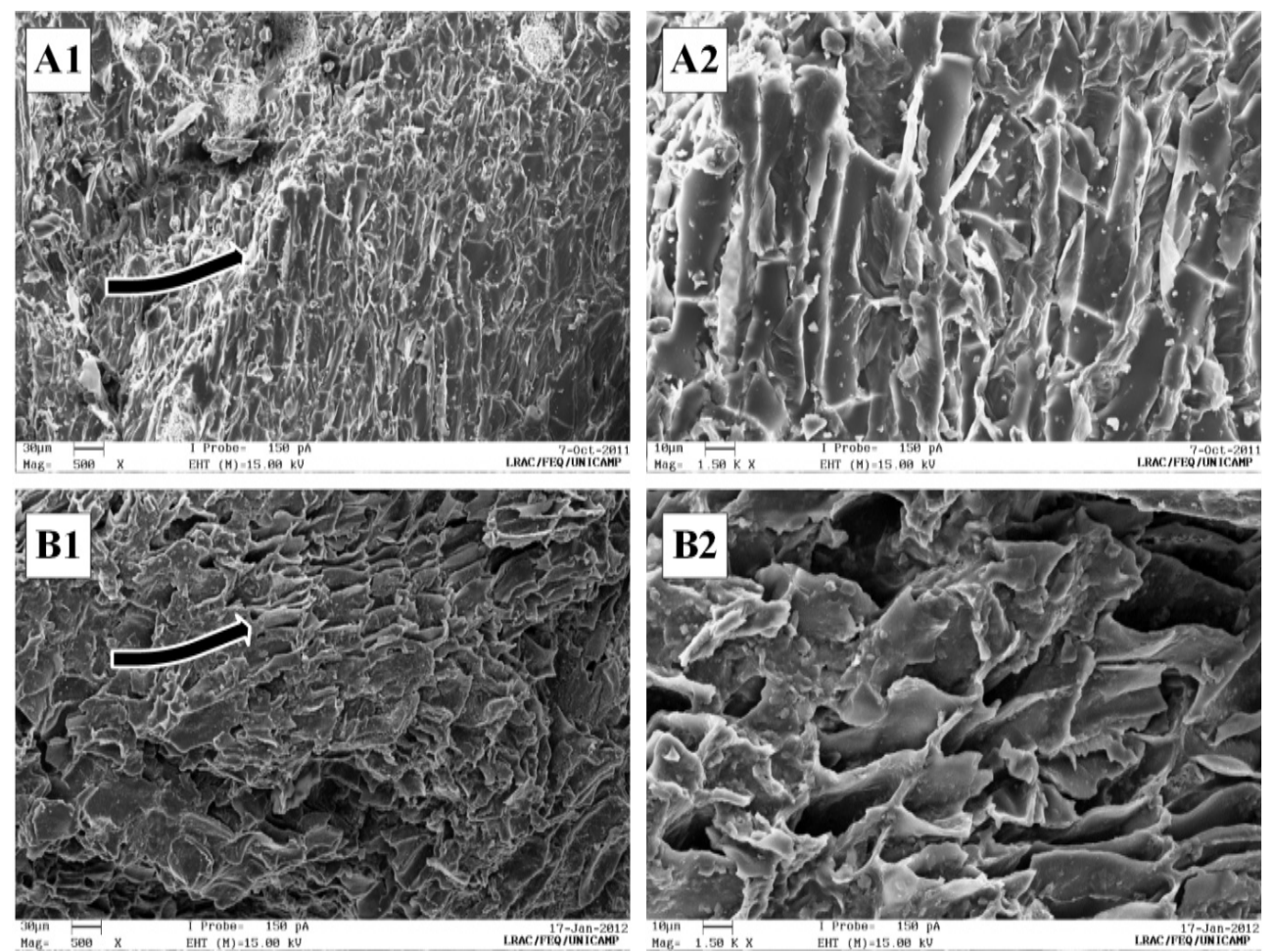

Figure 1. SEM images of (A) BGR in natura and (B) BGR after PLE. Numbers 1 and 2 correspond to magnification of 500x and 1500x, respectively
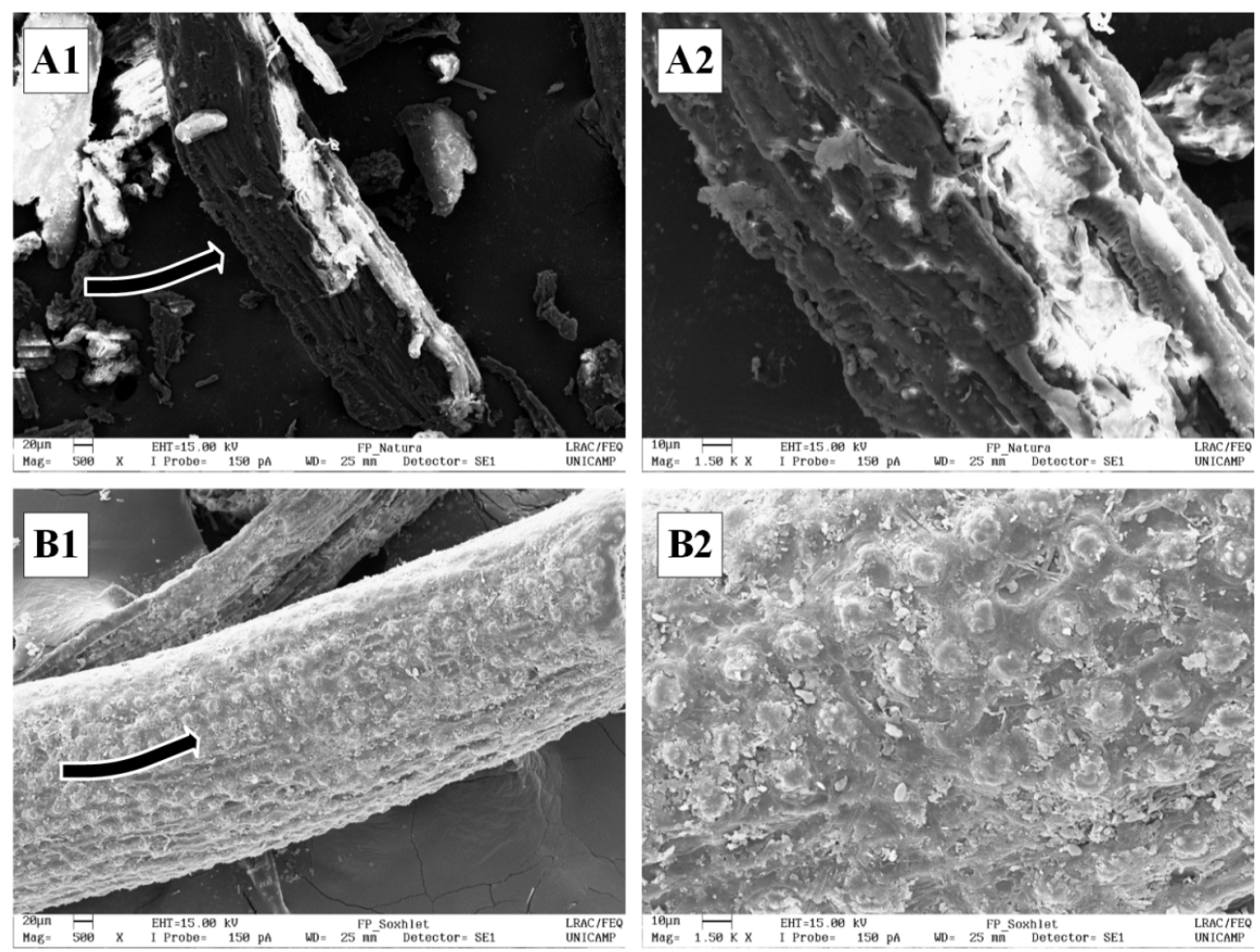

Figure 2. SEM images of (A) PPF before SE and (B) PPF after PLE. Numbers 1 and 2 correspond to magnification of 500x and 1500x, respectively 
In Figure 3 the annatto seeds can be observed before and after the SE and SFE processes. In both cases, the vegetal material was penetrated by the solvent after the extraction process, partially dragging lipids and starches from the annatto seeds. Starch in the vegetal structures is deposited in the form of relatively dense granules that range in size between 1- $100 \mu \mathrm{m}$, depending on the plant species. Starch is synthesized in special cell compartments formed by cellulose called amyloplasts [42, 43]. As observed in Figure 3 (A), the interior morphology of the annatto seeds showed an amyloplast structure that is formed when cellulose creates symmetrical spaces where granules of starch are hosted [43]. Starch in annatto seeds exhibits a form of round granules.

Studying the formation of the starch granules, lipids molecules form starch-lipid complexes in some plant species
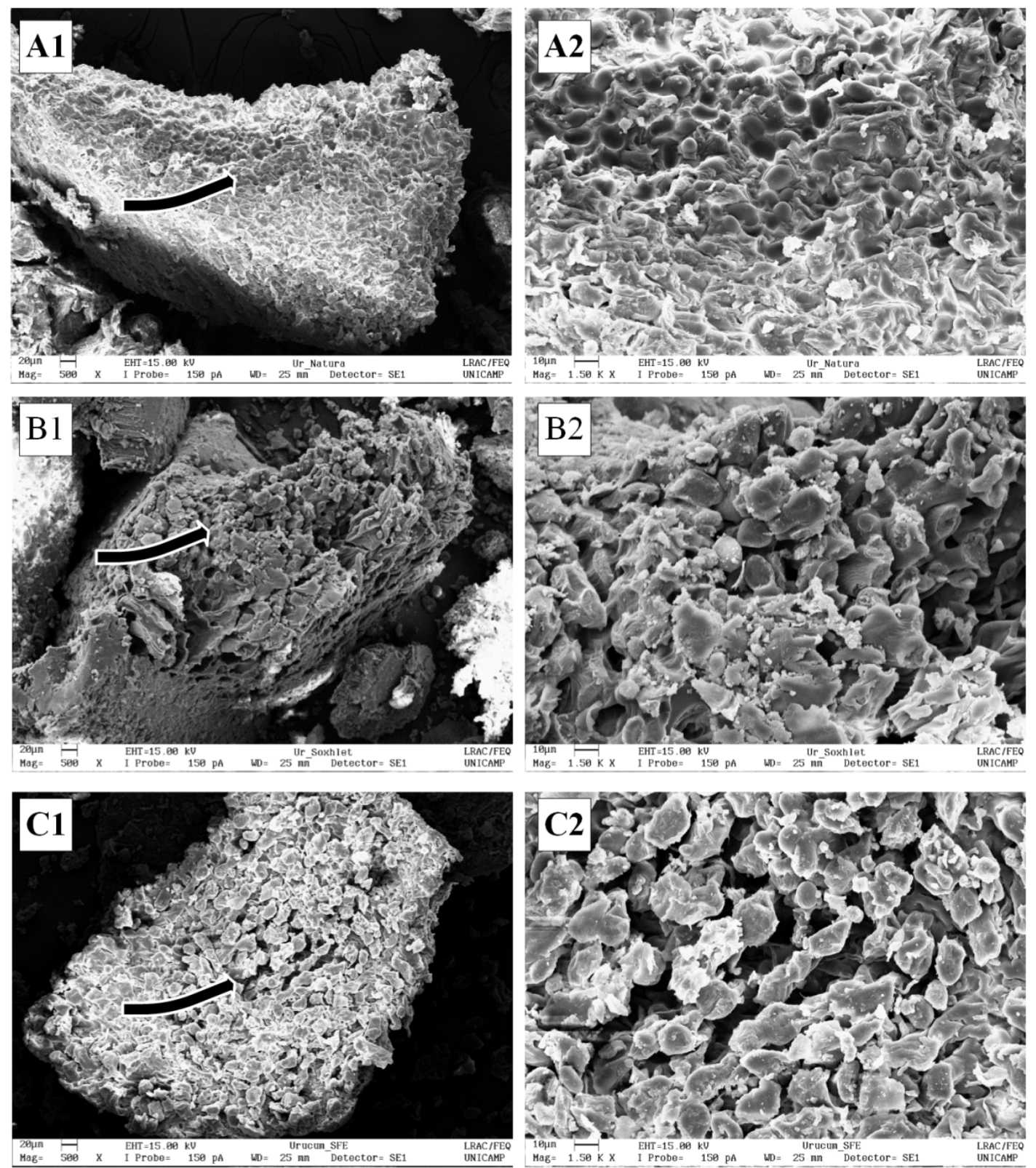

Figure 3. SEM images of (A) Annatto seeds in natura, and (B) DAS after SE and (C) DAS after SFE. Numbers 1 and 2 correspond to magnification of $500 x$ and $1500 x$, respectively 


\subsection{Hydrolysis Yield}

According to the results obtained for BGR, the best yields of RS and TRS for the hydrolysis process were obtained from BGR in natura. BGR pretreatment by the PLE process using water as the solvent most likely removed sugars present in the biomass along with the compounds of interest for the extraction. The pretreatment process may have caused a thermos-hydrolysis process at first because of the self-ionization properties of water. The BGR hydrolysis kinetics behavior is shown in Figure 4, for BGR in natura the sugars originally present in the biomass are most likely oligomers and monomers that are easier to hydrolyze as shown by both curves (RS and TRS yield). Hydrolysis kinetics for BGR in nature has a higher yield than those of BGR after the PLE process. The analysis of the kinetics behavior of the hydrochloric acid solutions showed that for the most dilute solution $(0.5 \% \mathrm{w} / \mathrm{w})$, acid hydrolysis increased during the initial processing time and kept growing throughout the operation. Despite this behavior, yields of sugar did not exceed those yields observed using higher acid concentrations. A reaction with an intermediate concentration $(2.5 \% \mathrm{w} / \mathrm{w})$ showed better results from the start of the reaction. The hydrolysis yield at a higher acid concentration $(5.0 \% \mathrm{w} / \mathrm{w})$ showed a high rate of RS and TRS production from hydrolysis at first, but this production rapidly decayed because the degradation rates of sugar monomers was greater than the oligomer hydrolysis at this acid concentration.

The products of interest generated by hydrolysis of vegetal biomass are pentoses and hexoses with various degrees of polymerization. Degradation of glucose due to the hydrolysis reaction produces compounds such as 5- hydroxymethyl furfural (5-HMF) and organic acids that have 5-HMF as a precursor, such as levulinic and formic acid [23].

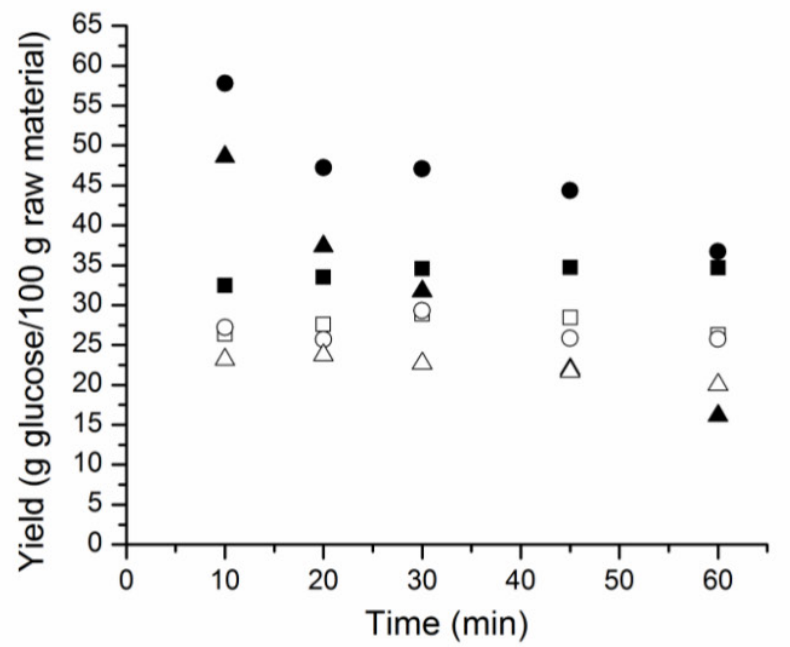

The kinetics of the hydrolysis of PPF, shown in Figure 5, does not indicate significant differences between PPF material before and after SE pretreatment. Extraction treatment did not alter the physical morphology and composition of the lignocellulosic compounds found in the PPF raw material. The PPF structure is highly resistant due to strong polysaccharides, such as cellulose and lignin. Regarding the acid concentrations used for PPF acid hydrolysis, the observed kinetics behavior between the acid concentration and hydrolysis yield is proportional. The hydrolysis rate is maintained with increasing operation time [24].

In Figure 6, the hydrolysis kinetics for Annatto seeds is shown. These curves suggest that defatted, SFE pretreated material was more easily hydrolysable than raw material in nature and also defatted, SE pretreated material, according to RS and TRS yields. The kinetic hydrolysis of Annatto and micrographs of its structure (Figures 5,6 and 7) can be explained by SE pretreatment removing more of the starch-lipid complex than SFE treatment [35].

Romero et al. [15] studied acid hydrolysis of residues generated by pruning olive trees using sulfuric acid solutions in concentrations from 0 to $32 \%(\mathrm{w} / \mathrm{w})$ and temperatures between 60 and $90^{\circ} \mathrm{C}$. These results showed that the cellulose and hemicellulose fractions that remain insoluble during the hydrolysis operation decrease proportionally with the increase in the acid solution concentration. When using dilute solutions, the authors observed that only the hemicellulose content decreased, whereas the cellulose fraction remained unchanged. When the acid concentration was greater than $4.5 \%(\mathrm{w} / \mathrm{w})$ of sulfuric acid, hydrolysis of cellulose started. On the other hand, the lignin content of these raw materials remained constant.

Figure 4. Acid hydrolysis of BGR in natura $(\boldsymbol{\bullet}, \bullet, \mathbf{\Lambda})$ and after PLE ( $\square, \circ, \Delta)$ using hydrochloric acid solution $0.5 \%(\bullet, \square), 2.5 \%(\bullet, \circ)$ and $5.0 \%(\mathbf{\Lambda}, \Delta)$, (w/w); respectively. a) RS yield (\%) and b) RTS yield (\%) 

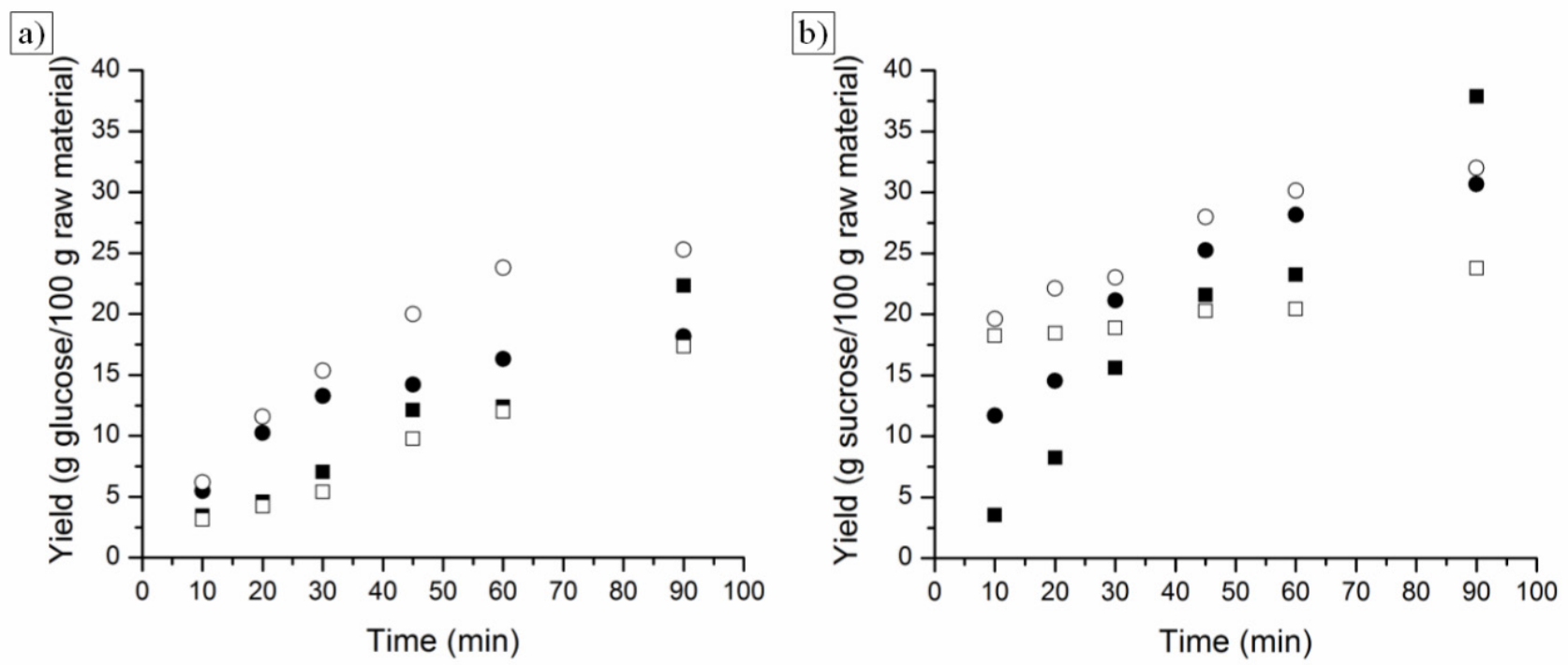

Figure 5. Acid hydrolysis of PPF ( $\bullet, \bullet)$ and PPF after SE (,,$\circ)$ using sulfuric acid solution $1.5 \%(\bullet, \square)$ and $3.0 \%(\bullet, \circ)$, (w/w); respectively. a) RS yield (\%) and b) RTS yield (\%)
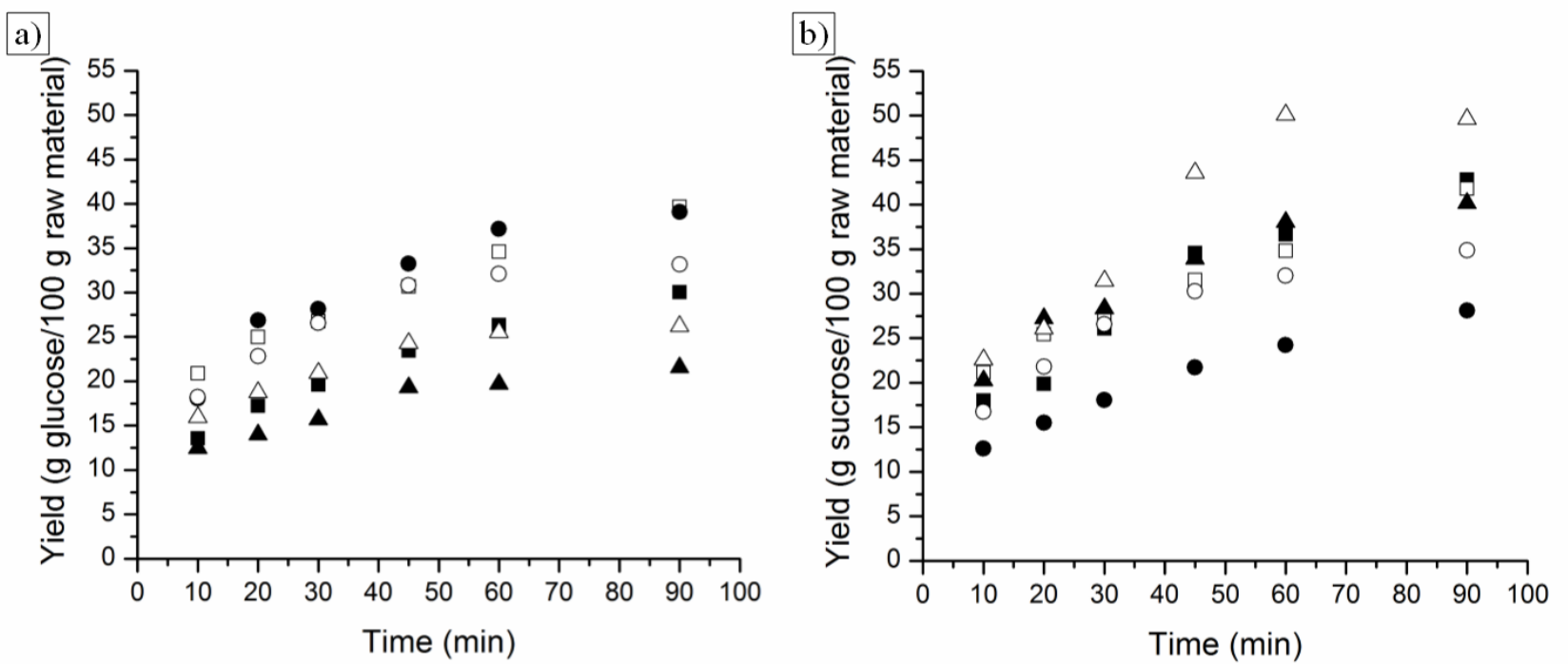

Figure 6. Acid hydrolysis of annatto seeds in natura $(\boldsymbol{\bullet}, \square)$, DAS after $\operatorname{SE}(\bullet, \circ)$ and DAS after SFE $(\boldsymbol{\Lambda}, \Delta)$ using sulfuric acid solution $1.5 \%(\mathbf{\bullet}, \bullet, \mathbf{\Lambda})$ and $3.0 \%(\square, \circ, \Delta),(\mathrm{w} / \mathrm{w})$; respectively. a) RS yield (\%) and b) RTS yield (\%)

\section{Conclusions}

Analysis of the observations from micrographs showed that the morphologies of the different biomasses changed after the extraction processes. The surfaces of the treated raw materials showed a considerable increase in porosity and roughness when compared with untreated materials.

The acid hydrolysis process showed different behaviors for each material that was hydrolyzed. All the plant materials studied belong to different vegetal groups, and the cell structures of these plants have polysaccharides in different forms and proportions. Acid hydrolysis parameters depended on the acid concentration and polysaccharide in the plant.

Extraction treatments preceding the acid hydrolysis process modified vegetal matrices in different ways. In BGR material, PLE pretreatment removed a large number of water-soluble molecules including structural polysaccharides. Brazilian ginseng in natura showed better yield results than raw material after PLE. The SE pretreatment of PPF modified the cellular structure and composition of the sample, although the polysaccharides in the PPF structure needed a more invasive treatment (mainly lignin) to have a more perceptible impact on hydrolysis. Hydrolysis kinetics in annatto seeds showed that SE and SFE pretreatments had different effects on the plant matrix.

\section{Perspectives and Future Trends}

The starch presence in the structure of annatto seeds has special importance, because of not only the oligomers and monomers produced but also because the starch market is constantly growing and requires a continuous search for 
products with features that satisfy industry needs. In addition to modified starch, the natural pigment bixin is also derived from annatto seeds.

The hydrolysis of vegetal matrices with special properties like the raw materials in this study could result in products with special aromas and colors. These materials have potential application in food formulations, and the sugars produced by these processes could be used as substrates in a wide range of processes.

\section{ACKNOWLEDGEMENTS}

Sylvia C. Alcázar-Alay and Fiorella P. Cardenas-Toro thank the Brazilian agency CAPES/PECPG for the doctoral fellowships (Processes 5532116 and 5945100, respectively). Diego T. Santos thanks FAPESP for the post-doctoral fellowship (2010/16485-5). M. A. A. Meireles thanks CNPq (301301/2010-7) for the productivity grant. The authors acknowledge CNPq (560914/2010-5) and FAPESP (2012/10685-8) for financial support. The authors thank Dr. Eliane G. Fabri from IAC for donating the annatto seeds.

\section{Acronyms}

Soxhlet extraction (SE), Pressurized liquid extraction (PLE), Supercritical fluid extraction (SFE), Scanning electron microscope (SEM), Reducing sugar (RS), Total reducing sugar (TRS), Microwave assisted extraction (MAE), Ultrasound-assisted extraction (UAE), Pulsed-electric field extraction (PEF), Enzyme-assisted extraction (EAE), Brazilian Ginseng Roots (BGR), Pressed Palm Fiber (PPF), Defatted Annatto Seeds (DAS), Solvent / Feed ratio (S/F).

\section{REFERENCES}

[1] Zabot, G. L., Moraes, M. N., Meireles, M. A. A., 2014 Supercritical Technology Applied to the Production of Bioactive Compounds: Research Studies Conducted at LASEFI from 2009 to 2013., Food Public Health, 4(2), 36-48.

[2] Azmir, J., Zaidul, I. S. M., Rahman, M. M., Sharif, K. M., Mohamed, A., Sahena, F., Jahurul, M. H. A., Ghafoor, K., Norulaini, N. A. N., Omar, A. K. M., 2013, Techniques for extraction of bioactive compounds from plant materials: A review., J. Food Eng., 117(4), 426-436.

[3] Escribano-Bailón, M. T., Santos-Buelga, C., Alonso, G. L., Salinas, M. R., 2002, Anthocyanin composition of the fruit of Coriaria myrtifolia L., Phytochem. Anal., 13(6), 354-357.

[4] De Castro, M. D. L. and García-Ayuso, L. E., 1998, Soxhlet extraction of solid materials: An outdated technique with a promising innovative future., Anal. Chim. Acta, 369(1-2), $1-10$.

[5] Dorta, E., Lobo, M. G., Gonzalez, M., 2012, Reutilization of Mango Byproducts: Study of the Effect of Extraction Solvent and Temperature on Their Antioxidant Properties., J. Food
Sci., 77(1), C80-C88.

[6] Soxhlet, F., 1879, Die gewichtsanalytische Bestimmung des Milchfettes., Dingler's Polytechnisches J., 232(5), 461-465.

[7] Richter, B. E., Jones, B. A., Ezzell, J. L., Porter, N. L., Avdalovic, N., Pohl, C., 1996, Accelerated Solvent Extraction: A technique for Sample Preparation., Anal. Chem., 68(6), 1033-1039.

[8] Nieto, A., Borrull, F., Pocurull, E., Marcé, R. M., 2010, Pressurized liquid extraction: A useful technique to extract pharmaceuticals and personal-care products from sewage sludge., TrAC, Trends Anal. Chem., 29(7), 752-764.

[9] Rodrigues, L. M., Alcázar-Alay, S. C., Petenate, A. J., Meireles, M. A. A., 2014, Bixin extraction from defatted annatto seeds., C. R. Chimie, 17(3), 268-283.

[10] Brunner, G., 2005, Supercritical fluids: technology and application to food processing., J. Food Eng., 67(1-2), 21-33.

[11] G. Brunner, Gas extraction: an introduction to fundamentals of supercritical fluids and the application to separation processes, Ed. Berlin, Germany: Springer, 1994, vol. 4.

[12] Moraes, M. N., Zabot, G. L., Prado, J. M., Meireles, M. A. A., 2013, ObtainingAntioxidants from Botanic Matrices Applying Novel Extraction Techniques., Food Public Health., 3(4), 195-214.

[13] Phitsuwan, P., Sakka, K., Ratanakhanokchai, K., 2013, Improvement of lignocellulosic biomass in planta: A review of feedstocks, biomass recalcitrance, and strategic manipulation of ideal plants designed for ethanol production and processability., Biomass Bioenergy, 58, 390-405.

[14] Gomez, L. D., Steele-King, C. G., McQueen-Mason, S. J., 2008, Sustainable liquid biofuels from biomass: the writing's on the walls., New Phytol., 178(3), 473-485.

[15] Romero, I., Ruiz, E., Castro, E., Moya, M., 2010, Acid hydrolysis of olive tree biomass., Chem. Eng. Res. Des., 88(5-6), 633-640.

[16] Moreschi, S. R. M., Leal, J. C., Braga, M. E. M., Meireles, M. A. A., 2006, Ginger and turmeric starches hydrolysis using subcritical water + CO2: The effect of the SFE pre-treatment., Braz. J. Chem. Eng., 23(2), 235-242.

[17] Rogalinski, T., Ingram, T., Brunner, G., 2008, Hydrolysis of lignocellulosic biomass in water under elevated temperatures and pressures., J. Supercrit. Fluids, 47(1), 54-63.

[18] Zhu, G., Zhu, X., Fan, Q., Wan, X., 2011, Recovery of biomass wastes by hydrolysis in sub-critical water., Resour. Conserv. Recycl., 55(4), 409-416.

[19] Cardenas-Toro, F. P., Forster-Carneiro, T., Rostagno, M. A., Petenate, A. J., Maugeri Filho, F., Meireles, M. A. A., 2014, Integrated supercritical fluid extraction and subcritical water hydrolysis for the recovery of bioactive compounds from pressed palm fiber., J. Supercrit. Fluids, 93, 42-48.

[20] Chin, S. X., Chia, C. H., Fang, Z., Zakaria, S., Li, X. K., Zhang, F., 2014, A Kinetic Study on Acid Hydrolysis of Oil Palm Empty Fruit Bunch Fibers Using a Microwave Reactor System., Energy Fuels, 28, 2589-2597.

[21] Li, Q., Ng, W. T., Puah, S. M., Bhaskar, R. V., Soh, L. S., Macbeath, C., Parakattil, P., Green, P., Wu, J. C., 2014, Efficient production of fermentable sugars from oil palm 
empty fruit bunch by combined use of acid and whole cell culture-catalyzed hydrolyses., Biotechnol. Appl. Biochem., 61(4), 426-431.

[22] Iranmahboob, J., Nadim, F., Monemi, S., 2002, Optimizing acid-hydrolysis: a critical step for production of ethanol from mixed wood chips., Biomass Bioenergy., 22(5), 401-404.

[23] Gurgel, L. V. A., Marabezi, K., Zanbom, M. D., Curvelo, A. A. D. S., 2012, Dilute Acid Hydrolysis of Sugar Cane Bagasse at High Temperatures: A Kinetic Study of Cellulose Saccharification and Glucose Decomposition. Part I: Sulfuric Acid as the Catalyst., Ind. Eng. Chem. Res., 51(3), 1173-1185.

[24] Ji, W., Shen, Z., Wen, Y., 2015, Hydrolysis of wheat straw by dilute sulfuric acid in a continuous mode., Chem. Eng. J., 260, 20-27.

[25] Sun, Y. and Cheng, J., 2002, Hydrolysis of lignocellulosic materials for ethanol production: a review., Bioresour. Technol., 83(1), 1-11.

[26] Leal, P. F., Kfouri, M. B., Alexandre, F. C., Fagundes, F. H. R., Prado, J. M., Toyama, M. H., Meireles, M. A. A., 2010 Brazilian Ginseng extraction via LPSE and SFE: Global yields, extraction kinetics, chemical composition and antioxidant activity., J.Supercrit. Fluids, 54(1), 38-45.

[27] Neto, A. G., Costa, J. M. L. C., Belati, C. C., Vinhólis, A. H. C., Possebom, L. S., Da Silva Filho, A. A., Cunha, W. R., Carvalho, J. C. T., Bastos, J. K., Silva, M. L. A., 2005, Analgesic and anti-inflammatory activity of a crude root extract of Pfaffia glomerata (Spreng) Pedersen., J. Ethnopharmacol., 96(1-2), 87-91.

[28] Nakamura, S., Chen, G., Nakashima, S., Matsuda, H., Pei, Y., Yoshikawa, M., 2010, Brazilian Natural Medicines. IV. New Noroleanane-Type Triterpene and Ecdysterone-Type Sterol Glycosides and Melanogenesis Inhibitors from the Roots of Pfaffia glomerata., Chem. Pharm. Bull., 58(5), 690-695.

[29] Santos, D. T., Barbosa, D. F., Broccolo, K., Gomes, M. T. M., Vardanega, R., Meireles, M. A. A., 2012, Pressurized organic solvent extraction with on-line particle formation by supercritical anti solvent processes., Food Public Health., 2(6), 231-240.

[30] Santos, D. T., Vardanega, R., Albarelli, J. Q., Ensinas, A. V., Marechal, F., Meireles, M. A., 2013, Energy Consumption Versus Antioxidant Activity of Pressurized Fluid Extracts from Pfaffia glomerata Roots., Chem. Eng. Transactions, 35, 1099-1104.

[31] França, L. F., and Meireles, M. A. A., 1997, Extraction of oil from pressed palm oil (Elaes guineensis) fibers using supercritical CO2., Food Sci. Technol., 17(4), 384-388.

[32] Prado, J. M., Forster-Carneiro, T., Rostagno, M. A., Follegatti-Romero, L. A., Maugeri Filho, F., Meireles, M. A. A., 2014, Obtaining sugars from coconut husk, defatted grape seed, and pressed palm fiber by hydrolysis with subcritical water., J. Supercrit. Fluids, 89, 89-98.
[33] J. Smith, and H. Wallin, "ANNATTO EXTRACTS, Chemical and Technical Assessment", Combined compendium of food additive specifications, in: 67th Joint FAO/WHO Expert Committee on Food Additives, 2006. vol.3, p.21.

[34] Preston, H. D., and Rickard, M. D., 1980, Extraction and chemistry of annatto., Food Chem., 5(1), 47-56.

[35] Albuquerque, C. L. C., and Meireles, M. A. A., 2012, Defatting of annatto seeds using supercritical carbon dioxide as a pretreatment for the production of bixin: Experimental, modeling and economic evaluation of the process., J. Supercrit. Fluids, 66, 86-95.

[36] Sluiter, A,. Hames, B., Hyman, D., Payne, C., Ruiz, R., Scarlata, C., Sluiter, J., Templeton, D., Wolfe, J., "Determination of total solids in biomass and total dissolved solids in liquid process samples"., National Renewable Energy Laboratory, Golden, CO, NREL Technical Report No. NREL/TP-510-42621, pp. 1-6, Mar. 2008.

[37] Thiex, N. J., Anderson, S., Gildemeister, B., 2003, Crude fat, diethyl ether extraction, in feed, cereal grain, and forage (Randall/Soxtec/submersion method): Collaborative study., J. AOAC Int., 86(5), 888-898.

[38] Thiex, N. J., Manson, H., Anderson, S., Persson, J. A., 2002, Determination of crude protein in animal feed, forage, grain, and oilseeds by using block digestion with a copper catalyst and steam distillation into boric acid: Collaborative study, J. AOAC Int., 85(2), 309-317.

[39] Sluiter, A., Hames, B., Ruiz, R., Scarlata, C., Sluiter, J., Templeton, D., 2008, "Determination of ash in biomass"., National Renewable Energy Laboratory, Golden, CO, NREL Technical Report No. NREL/TP-510-42622, pp. 1-5, Jan. 2008.

[40] Nelson, N., 1944, A photometric adaptation of the Somogyi method for the determination of glucose., J. Biol. Chem., 153(2), 375-380.

[41] Brunner, G., 2009, Near critical and supercritical water. Part I. Hydrolytic and hydrothermal processes., J. Supercrit. Fluids, 47(3), 373-381.

[42] Ellis, R. P., Cochrane, M. P., Dale, M. F. B., Duffus, C. M., Lynn, A., Morrison, I. M., Prentice, R. D. M., Swanston, J. S., Tiller, S. A., 1998, Starch production and industrial use., J. Sci. Food Agric., 77(3), 289-311.

[43] Smith A. M., 2001, The biosynthesis of starch granules., Biomacromolecules., 2(2), 335-341.

[44] Tester, R. F., Karkalas, J., Qi, X., 2004, Starch - Composition, fine structure and architecture., J. Cereal Sci., 39(2), 151-165.

[45] Braga, M. E. M., Moreschi, S. R. M., Meireles, M. A. A., 2006, Effects of supercritical fluid extraction on Curcuma longa L. and Zingiber officinale R. starches., Carbohydr. Polym., 63(3), 340-346. 